\title{
Kinetics of solid-state reactions between zirconium thin film and silicon carbide at elevated temperatures
}

\author{
E. G. Njoroge ${ }^{a^{*}}$, C. C. Theron ${ }^{\text {a }}$, J. B. Malherbe ${ }^{a}$, O. M. Ndwandwe ${ }^{b}$
}

(a) Department of Physics, University of Pretoria, Pretoria, 0002, South Africa

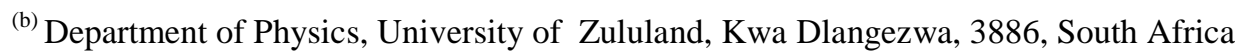

\begin{abstract}
Solid state reactions between a thin film $(133 \mathrm{~nm})$ of $\mathrm{Zr}$ and bulk single crystalline $6 \mathrm{H}-\mathrm{SiC}$ substrates have been studied at temperatures between $600{ }^{\circ} \mathrm{C}$ and $850{ }^{\circ} \mathrm{C}$ for durations of 30,60 and 120 min under high vacuum conditions. The deposited film and reaction zones were investigated by Rutherford backscattering spectrometry (RBS) and X-ray diffraction. The RBS spectra were simulated in order to obtain the deposited layer thickness, reaction zone compositions and reaction zone thickness. The as-deposited spectra fit well with those annealed at $600{ }^{\circ} \mathrm{C}$, thus showing there were no reactions taking place. At temperatures of $700{ }^{\circ} \mathrm{C}$ and above, $\mathrm{Zr}$ reacted with the $\mathrm{SiC}$ substrate and formed a mixed layer of $\mathrm{Zr}$ carbide $\left(\mathrm{ZrC}_{x}\right)$ and $\mathrm{Zr}$ silicides $\left(\mathrm{ZrSi} \mathrm{Zr}_{2} \mathrm{Si}\right.$ and $\left.\mathrm{Zr}_{5} \mathrm{Si}_{3}\right)$. Annealing at $850{ }^{\circ} \mathrm{C}$ for $240 \mathrm{~min}$ revealed that all the deposited $\mathrm{Zr}$ had completely reacted. The interface reaction follows the parabolic growth law thereby indicating diffusion controlled reaction kinetics. The activation energy for the diffusion process obtained was $1.6 \mathrm{eV}$ in the relatively narrow temperature range 700 $850{ }^{\circ} \mathrm{C}$.
\end{abstract}

Keywords: $\mathrm{Zr}, \mathrm{SiC}$, interface, reactions, kinetics.

\section{Introduction}

Silicon carbide $(\mathrm{SiC})$ is a ceramic material used in high temperature, high frequency and high power structural and electronic devices [1] and [2]; conventional semiconductors cannot adequately perform in these conditions. But SiC possesses many favourable chemical, physical and electronic properties for these applications such as; high thermal conductivity, high thermal stability, chemical inertness, high breakdown electric field strength, and wide band-gap [1] and [2]. $\mathrm{SiC}$ in a monolithic ceramic form, is used for fuel kernel encapsulation in tri structural-isotropic (TRISO) particles [3], [4] and [5]. TRISO fuel particles were developed for use in high temperature gas cooled reactors (HTGRs) like the pebble bed modular reactor (PBMR). SiC is known to provide structural integrity to the fuel kernel and is the main diffusion barrier of metallic fission products in coated fuel particles [3], [4] and [5].

Zirconium is a transition metal with a high melting point $\left(1850{ }^{\circ} \mathrm{C}\right)$. It has been proposed for use in metal matrix microencapsulated (M3) fuels being developed for use in light water reactors (LWRs) [6] and [7]. The M3 fuel rod, consist of coated fuel particles embedded in a $\mathrm{Zr}$ metal matrix. The $\mathrm{Zr}$ yield in most nuclear fuels has been found to be high compared to other fission products $[8]$. $\mathrm{Zr}$ has also been proposed as a stable metal contact to $\mathrm{SiC}$ for high temperature electronic operations [9].

The fabrication of M3 fuel rods involves Hot Isostatic Pressing (HIP) and extrusion processes which require high temperatures. These high operating and fabrication temperatures could induce reactions at the $\mathrm{Zr} / \mathrm{SiC}$ interface of M3 fuels. Reactions between fission products and SiC in TRISO fuel particles are known to decrease the thickness of the SiC layer and may result in fission product release [10]. When SiC based electronic devices are operated at high temperatures and for long durations, degradation or alteration of the device performance is usually observed. The degradation arises from interdiffusion and reactions occurring at the metal/SiC interface [11]. For these applications of $\mathrm{SiC}$ as a structural and electronic material, the metal/SiC

*Corresponding author: E. G. Njoroge, e-mail: eric.njoroge@up.ac.za 
interactions and their thermal stability are of fundamental importance and need to be understood clearly.

Reactive phase formation in thin films is known to differ from bulk diffusion couples [12], for example, the stable phases formed in thin films are known to form sequentially and metastable compounds can appear in the reaction zone. Previous studies on the $\mathrm{Zr} / \mathrm{SiC}$ interface have involved the use of bulk $\mathrm{Zr}$ metal in contact with $\mathrm{SiC}[13]$ and [14]. In this study, the solid-state reactions between thin $\mathrm{Zr}$ films and single-crystalline $6 \mathrm{H}-\mathrm{SiC}$ polytype substrates at elevated temperatures were investigated. The reaction products formed and reaction kinetics are discussed in the temperature range of $600-1000^{\circ} \mathrm{C}$.

\section{Experimental method}

The $6 \mathrm{H}-\mathrm{SiC}$ single-crystal wafers were purchased from Pam-Xiamen (China). The bulk semi-insulating wafers, were single-face polished with Si face epiready, 2 inch diameter, $330 \mu \mathrm{m}$ thick, micro pipe density of $<30 \mathrm{~cm}^{-2}$ and with root mean square (rms) surface roughness of less than $0.5 \mathrm{~nm}$. The $\mathrm{Zr}$ sputtering target (AJA international Inc.) was 2 inches in diameter and 0.25 inches thick with $99.5 \%$ purity. Thin $\mathrm{Zr}$ films were sputter deposited on the $6 \mathrm{H}-\mathrm{SiC}$ wafers by an AJA international Inc. Orion 5 sputtering system. The $\mathrm{SiC}$ wafer was mounted on a rotating sample holder to ensure an uniform deposited layer. The chamber was pumped down to a base pressure of $10^{-7}$ Torr and then backfilled with Ar gas to a pressure of $10^{-3}$ Torr. The Ar gas flow was kept constant at $8 \mathrm{sscm} / \mathrm{min}$. The $\mathrm{Zr}$ target (DC sputtering) and the $\mathrm{SiC}$ (RF sputtering) substrate were sputter-cleaned for 10 min using Ar plasma before the room temperature sputtering was done. This ensured the removal of the native oxide layer from the $\mathrm{SiC}$ wafer and a clean $\mathrm{Zr}$ target surface for sputtering, since $\mathrm{Zr}$ readily oxidizes in air.

The sputtering rate of the $\mathrm{Zr}$ thin film was calculated to be $\sim 7 \mathrm{~nm} / \mathrm{min}$ and the sputter time was chosen to achieve a nominal thickness of $140 \mathrm{~nm}$. The $\mathrm{Zr} / \mathrm{SiC}$ diffusion couples were cleaved into $5 \times 5 \mathrm{~mm}$ pieces using a diamond scriber and were placed in a desiccator when not being analysed. The samples were annealed in a (high vacuum) $\mathrm{HV}$ quartz tube furnace at temperatures of $600{ }^{\circ} \mathrm{C}, 700{ }^{\circ} \mathrm{C}, 760{ }^{\circ} \mathrm{C}, 800{ }^{\circ} \mathrm{C}$ and $850{ }^{\circ} \mathrm{C}$ for 30,60 and $120 \mathrm{~min}$. The furnace was preheated to the desired temperature and then drawn over the quartz tube with the sample inside. After the annealing time was achieved, the furnace was pulled away from the quartz tube to allow the sample to cool down. This procedure ensured minimum heating and cooling times for the samples. The HV annealing at a base pressure of around $10^{-7}$ mbar was necessary to reduce oxidation of $\mathrm{Zr}$ during the heat treatment. Some of the samples were also annealed at $1000{ }^{\circ} \mathrm{C}$ for $120 \mathrm{~min}$ to reach the thermal equilibrium state of the $\mathrm{Zr} / \mathrm{SiC}$ system.

All the samples were analysed by Rutherford backscattering spectrometry (RBS) before and after annealing. The energy of the $\mathrm{He}^{+}$ions was $1.6 \mathrm{MeV}$ with a scattering angle of $165^{\circ}$ and the sample was tilted by a goniometer to avoid channelling. RBS analysis was performed to obtain the elemental composition of the as-deposited and annealed samples, the thickness of deposited $\mathrm{Zr}$ film and the thickness of the reaction zone. Grazing incidence X-ray diffraction (GIXRD) and wide angle XRD analysis done using a Bruker D8 Advanced XRD system with a $\mathrm{CuK} \alpha \mathrm{X}$-ray radiation source. For GIXRD analysis, the X-ray incident beam angle was kept at an angle of $3^{\circ}$ relative to the surface of the sample and the diffraction pattern collected by a detector rotated by a goniometer from $15^{\circ}$ to $90^{\circ}$. Wide-angle XRD analysis was also performed on the as-deposited and annealed samples. The two-theta radiation source angle was maintained at $20^{\circ}$ and the detector angle scan was from $20^{\circ}$ to $110^{\circ}$.

\section{Results and discussion}

The aim of this study was to investigate the phases formed at the $\mathrm{Zr} / \mathrm{SiC}$ interface and the reaction kinetics of the system. According to the ternary phase diagram of $\mathrm{Zr}-\mathrm{Si}-\mathrm{C}$ system at $1200{ }^{\circ} \mathrm{C}$ [15], interface reactions are expected to occur between $\mathrm{Zr}$ and $\mathrm{SiC}$ since no tie-line exists between the $\mathrm{Zr}$ and $\mathrm{SiC}$ phases. SiC reacts with most metals and the reaction temperatures of $\mathrm{SiC}$ with metals are usually greater than those of $\mathrm{Si}$ with the same metals [16]. The reaction products formed at the interface and the interface morphology of metal/SiC reaction zone is dependent on the metal in contact with $\mathrm{SiC} \mathrm{[17].} \mathrm{For} \mathrm{example,} \mathrm{refractory} \mathrm{metals} \mathrm{form} \mathrm{carbides} \mathrm{and}$ silicide when in contact with $\mathrm{SiC}$ since they are strong carbide forming metals [18].

RBS spectra were obtained after each annealing time to determine the growth rate of the $\mathrm{Zr} / \mathrm{SiC}$ reaction zone. The RBS spectra of the as-deposited $\mathrm{Zr} / \mathrm{SiC}$ sample is displayed in Fig. 1(a) along with the simulated spectra done using the RUMP [19] computer code. The arrows indicate the surface positions of the respective elements. The as-deposited $\mathrm{Zr}$ film exhibits a step starting at $1.42 \mathrm{MeV}$; this is attributed to hafnium which inherently 
occurs in $\mathrm{Zr}$ metal in trace amounts. From the RUMP simulations, the Hf concentration in the deposited layer is about $0.2 \%$. The thickness of the as-deposited $\mathrm{Zr}$ film was calculated using RUMP and was found to be $133 \mathrm{~nm}$. All the spectra of samples annealed at $600{ }^{\circ} \mathrm{C}$ were found to perfectly overlay with the as-deposited samples and hence are not reported here.
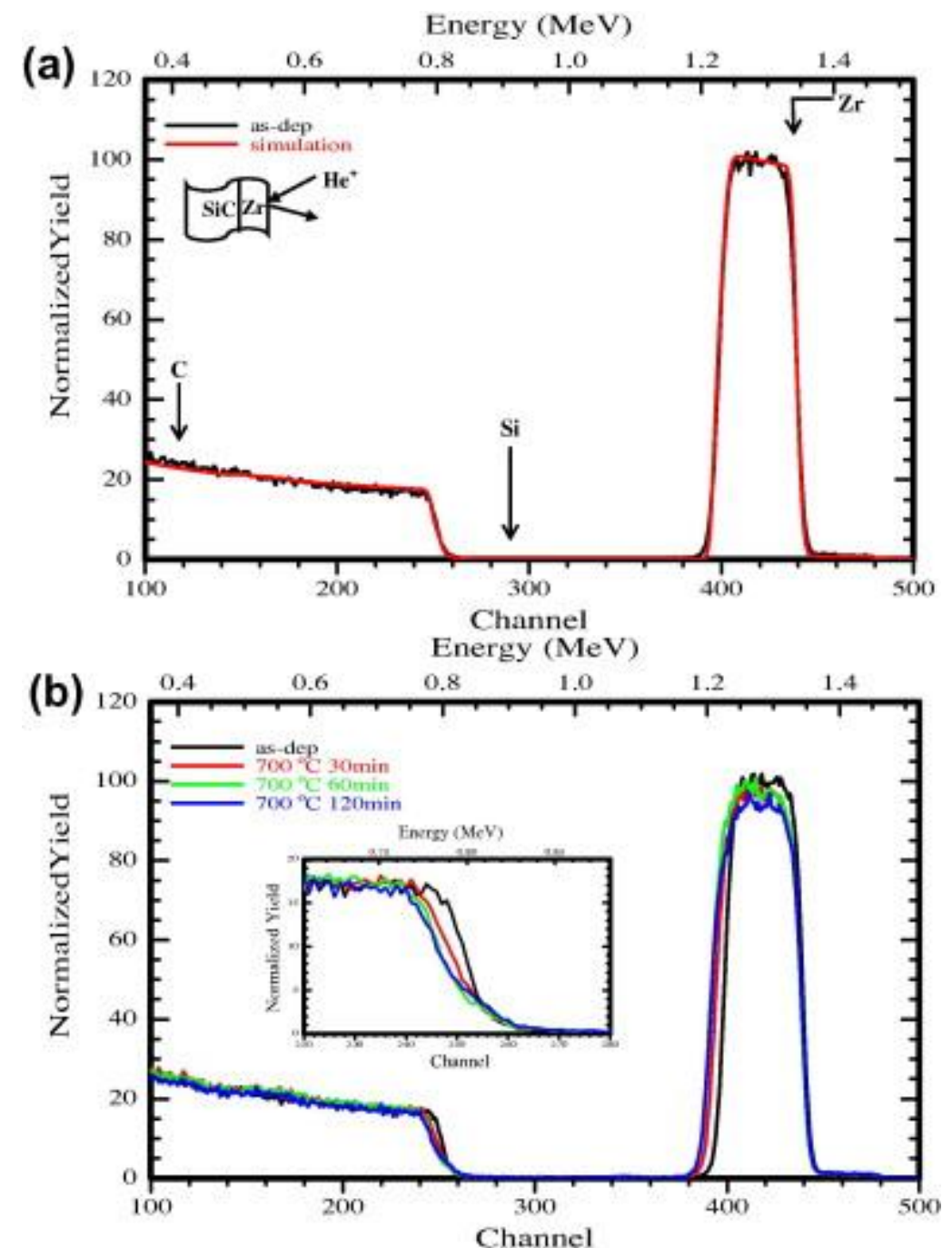

Fig. 1. (a) Raw RBS spectra of as-deposited $\mathrm{Zr} / \mathrm{SiC}$ with RUMP simulation spectrum. (b) Overlay of asdeposited and $700{ }^{\circ} \mathrm{C}$ annealed samples with insert of magnified portion from channel 200-300.

The RBS spectra of the as-deposited and annealed samples at $700{ }^{\circ} \mathrm{C}$ for 30 and $60 \mathrm{~min}$ as seen in Fig. 1(b), shows a reduction in the $\mathrm{Zr}$ peak height with increasing annealing time. After annealing, the back edge (lower energy) of the $\mathrm{Zr}$ signal has a progressive shift towards lower energy channels. A similar shift is observed on the high energy Si edge, which tends to shift toward lower energy channels with annealing time; this indicates that interdiffusion is taking place. For reactions to occur at the interface, $\mathrm{SiC}$ has to dissociate to its elemental constituents, that is, carbon and silicon [16]. This dissociation of $\mathrm{SiC}$ can be catalytically enhanced by the reaction metal, because the accepted dissociation temperature of $\mathrm{SiC}$ is $2700{ }^{\circ} \mathrm{C}$ [3]. However, it must be noted that SEM investigations have shown that the surface decomposition of $\mathrm{SiC}$ is already visible at $1300{ }^{\circ} \mathrm{C}$ [20]. After dissociation, $\mathrm{C}$ and $\mathrm{Si}$ then diffuse from the interface into the $\mathrm{Zr}$ metal and $\mathrm{Zr}$ diffuses from the interface into $\mathrm{SiC}$. Although just visible for $60 \mathrm{~min}$ anneal, especially, the sample annealed at $700{ }^{\circ} \mathrm{C}$ for 120 min, shows there is a reduction in height and a further shift to lower energies of the $\mathrm{Zr}$ signal, this is accompanied with the appearance of a small step at the high energy edge of the Si signal. This is a clear indication of the beginning of formation of $\mathrm{Zr}$ silicides.

This shift to higher energies by $\mathrm{Si}$ is observed to increase with the annealing duration indicating a growing reaction zone. These results indicate that the $\mathrm{Zr} / \mathrm{SiC}$ interface begins to react at temperature of $700{ }^{\circ} \mathrm{C}$ with the formation of zirconium carbide and silicides. Annealing at $760{ }^{\circ} \mathrm{C}$ and $800{ }^{\circ} \mathrm{C}$, the step on the Si edge continues 
to grow towards the Si surface channel indicating lateral growth of the reaction zone. It can also be observed in Fig. 2(a) and (b) that a step starts to develop on the low energy side of the Zr signal. This step gets wider with increase in annealing temperature up to $850^{\circ} \mathrm{C}$ spectra not shown. At this temperature, a plateau appears at the top of the $\mathrm{Zr}$ signal, which indicates that the deposited $\mathrm{Zr}$ layer has fully reacted with SiC. The Si signal appears at its surface channel position after annealing at $850{ }^{\circ} \mathrm{C}$ for $120 \mathrm{~min}$ indicating that $\mathrm{Si}$ is present from the shifted interface all the way to the surface of this sample. The comparison of the $\mathrm{Zr}$ peak total areal counts of the asdeposited with the annealed samples was found to remain constant indicating that there was no loss of deposited $\mathrm{Zr}$ atoms due to delamination during the annealing process. The solid-state reactions at the $\mathrm{Zr} / \mathrm{SiC}$ interface appear to have stopped when the sample was annealed at $850{ }^{\circ} \mathrm{C}$ for $120 \mathrm{~min}$. Further annealing at this temperature for four hours and at $900{ }^{\circ} \mathrm{C}$ and $1000{ }^{\circ} \mathrm{C}$ for two hours, reveals no changes in the reaction zone. The RBS spectra of samples annealed at $900{ }^{\circ} \mathrm{C}$ and $1000{ }^{\circ} \mathrm{C}$ exactly overlay those of samples annealed at $850{ }^{\circ} \mathrm{C}$ for two hours indicating that the reactions have stopped and the system is at a state of equilibrium, these spectra have not been reported here.
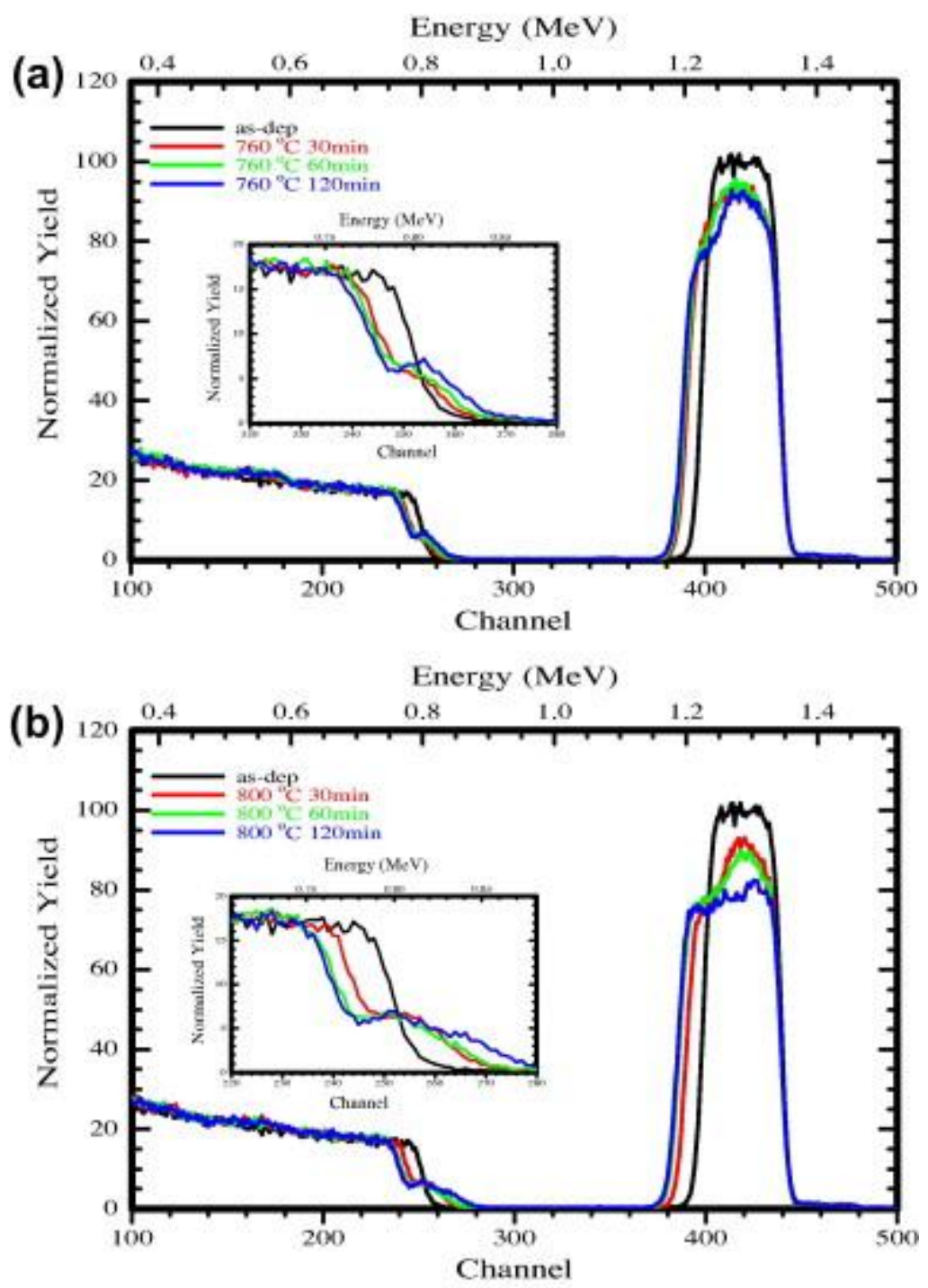

Fig. 2. (a) Overlay of RBS spectra of as-deposited and $760{ }^{\circ} \mathrm{C}$ and (b) $800{ }^{\circ} \mathrm{C}$ annealed samples with inserts of magnified portion from channel 200-300.

XRD measurements were performed to identify the phase and crystallinity of the deposited thin film and phases formed in the reaction zone. Grazing incidence X-ray diffraction spectra of samples annealed from $700{ }^{\circ} \mathrm{C}$ to $850{ }^{\circ} \mathrm{C}$ for 30 and $60 \mathrm{~min}$ (see Fig. 3 (a) and (b)) revealed that the deposited thin Zr film was amorphous. After thermal annealing, some crystalline phases were observed to be forming at the $\mathrm{Zr} / \mathrm{SiC}$ interface. Wide-angle XRD analysis was performed on the as-deposited and annealed samples since diffraction peaks could not be picked from GIXRD analysis of the samples. The wide angle XRD spectra of as-deposited sample revealed peaks of unreacted $\mathrm{Zr}$ and $\mathrm{SiC}$ substrate, but no zirconium silicide or carbide peaks were seen. For the sample 
annealed at $1000{ }^{\circ} \mathrm{C}$ for $2 \mathrm{~h}$, no unreacted $\mathrm{Zr}$ was visible, but a strong peak from the SiC substrate can be observed. The various $\mathrm{Zr}$ silicide and carbide phases $\mathrm{Zr}_{2} \mathrm{Si}, \mathrm{ZrSi}, \mathrm{Zr}_{5} \mathrm{Si}_{3}$ and $\mathrm{ZrC}$ are observed to be present.
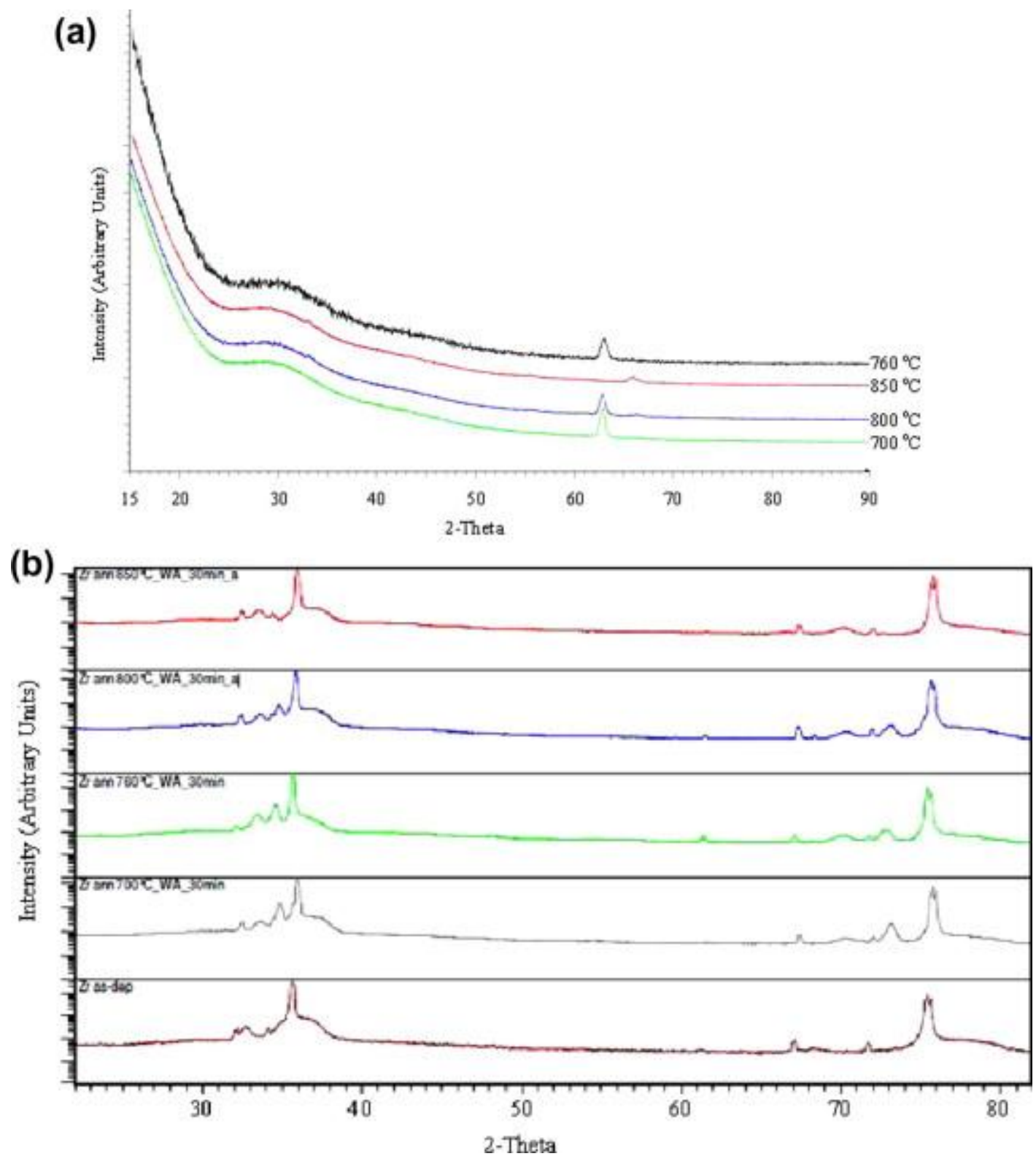

Fig. 3. (a) GIXRD and (b) wide angle XRD spectra of as-deposited, annealed at $700{ }^{\circ} \mathrm{C}, 760{ }^{\circ} \mathrm{C}, 800{ }^{\circ} \mathrm{C}, 850{ }^{\circ} \mathrm{C}$ and $900{ }^{\circ} \mathrm{C}$ samples.

From the $\mathrm{Zr}-\mathrm{Si}-\mathrm{C}$ ternary phase diagram [13] there is only one phase in either of the $\mathrm{Si}-\mathrm{C}$ and $\mathrm{Zr}-\mathrm{C}$ binary systems, that is, $\mathrm{SiC}$ and $\mathrm{ZrC}$ respectively. $\mathrm{The} \mathrm{Zr}-\mathrm{Si}$ side of the ternary phase diagram shows that there are seven silicides that can occur and since no tie-line exists between $\mathrm{Zr}$ and $\mathrm{SiC}$, these reactions are expected to occur. $\mathrm{Zr}$ is a strong carbide former based on the negative enthalpies of formation. $\mathrm{ZrC}$ has a value of $-202.9 \mathrm{~kJ} / \mathrm{mol}[21]$ which is much lower than all the silicides occurring in the system and is expected to be the dominant phase in the reaction zone.

A kinetics study was performed by measuring the growth of the total reaction zone thickness as a function of time at different temperatures. Four different temperatures $\left(700{ }^{\circ} \mathrm{C}, 760{ }^{\circ} \mathrm{C}, 800{ }^{\circ} \mathrm{C}, 850{ }^{\circ} \mathrm{C}\right)$ were used in this study and samples were annealed for three different time durations $(30,60,120 \mathrm{~min})$ at each temperature. In reaction kinetics investigations, it is important to identifying the reaction mechanism, namely, diffusioncontrolled or reaction-controlled, the activation energies and corresponding pre-exponential factors. The $\mathrm{Zr} / \mathrm{SiC}$ interface reaction was assumed to be diffusion-controlled because the growth of the reaction layer followed a parabolic growth law with respect to annealing time. The resulting squares of the interface layer thickness were 
plotted against the annealing time as seen in Fig. 4(a). Straight lines were obtained using a linear fit at the particular annealing temperatures. The growth of compounds at an interface between dissimilar materials is often expressed as $\left(x-x_{o}\right)^{2}=k t$, where $x$ is the distance from original interface $x_{o}$ to new interface, $t$ is the annealing duration, and $k$ is the reaction rate constant. This equation gives the parabolic relationship between the thickness of the reaction zone and time. The activation energy for the reaction zone growth is obtained from the Arrhenius-type equation, $k=k_{o} \exp (-Q / R T)$, where $k$ is the reaction rate constant for growth, $k_{0}$ is the preexponential factor, $Q$ the activation energy for the growth of the reaction zone (i.e. the interdiffusion of the reaction species), $T$ the temperature in Kelvin and $R$ the gas constant [22]. The reaction rate constant $k$, is dependent on the annealing temperature, as can be observed in Fig. 4(a). The annealed $\mathrm{Zr}-\mathrm{SiC}$ reaction zone was observed to grow following the parabolic law. This type of growth indicates that the reaction between $\mathrm{Zr}$ and $\mathrm{SiC}$ was controlled by a diffusion process. From the Arrhenius plot in Fig. 4(b) we obtained the activation energy, $Q$ of $1.6 \mathrm{eV}$ and pre-factor $k_{0}$ equal to $3.6 \times 10^{-4} \mathrm{~cm}^{2} / \mathrm{s}$. The data can be fitted by a single activation energy in this temperature range. This indicates that one particular diffusing step is rate limiting [23]. The activation energies measured by Thompson and $\mathrm{Tu}[24]$ for growth processes of silicides has been found to range between 1.1 and $1.5 \mathrm{eV}$. These values are low and are indicative of grain boundary diffusion process.
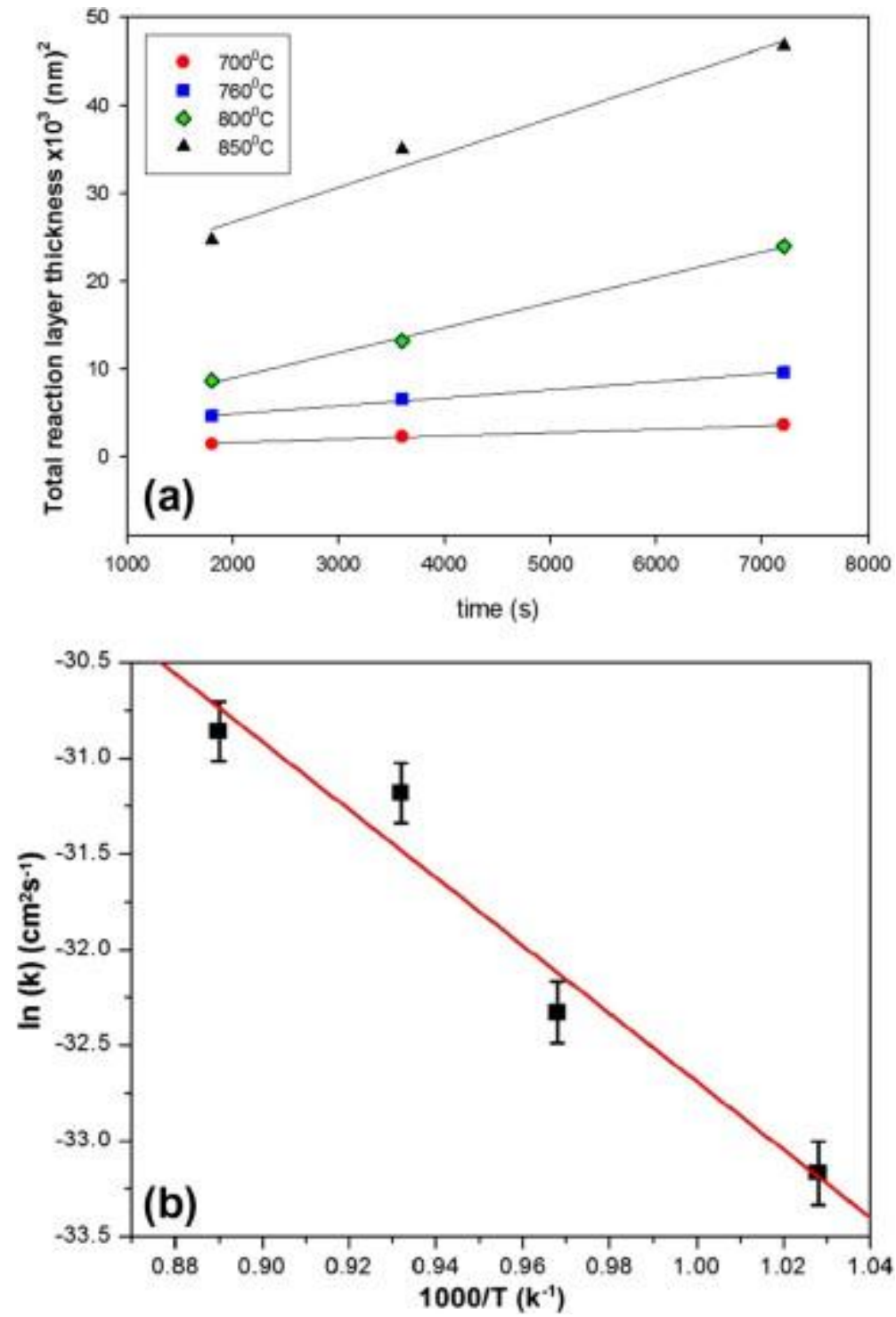

Fig. 4. (a) Plot of the square of the thickness of the reaction zone versus annealing time for the reaction between $\mathrm{Zr}$ and $\mathrm{SiC}$ at $700-850^{\circ} \mathrm{C}$ (b) An Arrhenius plot of the $\mathrm{Zr} / \mathrm{SiC}$ reaction constant $k$.

Similar studies on the interface reactions between bulk films of $\mathrm{Zr}$ on $\mathrm{SiC}$ have been done. The phases formed in the $\mathrm{Zr} / \mathrm{SiC}$ reaction zone observed by Fukai [13] are similar to those by Bhanumurthy and Schmid-Fetzer [14]. These include: granular $\mathrm{ZrC}_{x}, \mathrm{Zr}_{2} \mathrm{Si}, \mathrm{ZrC}$ and a ternary phase $\mathrm{Zr}_{5} \mathrm{Si}_{3} \mathrm{C}_{x}$. Bhanumurthy and Schmid-Fetzer also performed a kinetic study of the $\mathrm{Zr} / \mathrm{SiC}$ system and parabolic growth was observed for the phases formed in the 
whole reaction zone. They obtained activation energy, $Q$ as $1.4 \mathrm{eV}$ and pre-exponential factor $k_{0}$ equal to $3.4 \times 10^{3} \mu \mathrm{m} / \mathrm{s}^{1 / 2}\left(1.2 \times 10^{-1} \mathrm{~cm}^{2} / \mathrm{s}\right)$. The activation energy is close to the value obtained in this study. Although the investigations of Bhanumurthy and Schmid-Fetzer involved bulk $\mathrm{Zr}$ film on SiC, the fact that the activation energy for the bulk film case is close to the thin film case indicates that grain boundary diffusion dominates in both cases.

The reactions at the $\mathrm{Zr} / \mathrm{SiC}$ interface have practical implications. It explains the failure of $\mathrm{Zr}$ contacts on $\mathrm{SiC}$ for electronic applications at high temperatures and also the degradation of $\mathrm{Zr} / \mathrm{SiC}$ interfaces in structural composite applications. There is a discrepancy between silver diffusion coefficients in the SiC layer in TRISO particles measured in a reactor and in laboratories [25]. One of the explanations for this discrepancy is the influence of reactions between the $\mathrm{SiC}$ and other metallic fission products like $\mathrm{Pd}$, which also forms a silicide [26]. Since $\mathrm{Zr}$ is also a fission product, the reactions between $\mathrm{Zr}$ and $\mathrm{SiC}$ have implications for the integrity of the $\mathrm{SiC}$ layer in the TRISO particle.

\section{Conclusion}

It is observed that the metal $\mathrm{Zr}$ reacts with $\mathrm{SiC}$ in a relatively narrow range of temperature. $\mathrm{The} \mathrm{Zr} / \mathrm{SiC}$ interface interdiffusion starts at $700{ }^{\circ} \mathrm{C}$. The carbide $\mathrm{ZrC}$ and metal rich silicides start forming at the $\mathrm{Zr} / \mathrm{SiC}$ interface at a temperature of $700{ }^{\circ} \mathrm{C}$ and annealing period of $120 \mathrm{~min}$ and are present at $760{ }^{\circ} \mathrm{C}, 800{ }^{\circ} \mathrm{C}$ and $850{ }^{\circ} \mathrm{C}$. It is observed that $\mathrm{Zr}$ initially diffuses into $\mathrm{SiC}$ with the formation of metal rich silicides and $\mathrm{ZrC}$ with higher reaction rates measured at high temperatures. Reaction zone and hence the thinning of the SiC substrate is diffusion controlled and grows parabolic with time. The reactions at the $\mathrm{Zr} / \mathrm{SiC}$ interface could explain the failure of $\mathrm{Zr}$ contacts on $\mathrm{SiC}$ for electronic applications at high temperatures and the degradation of $\mathrm{Zr} / \mathrm{SiC}$ interfaces in structural composite applications.

\section{Acknowledgement}

The authors wish to thank Mr. T. Ntsoane and Dr. A. Venter from Necsa for their assistance with XRD analysis.

\section{References}

[1] V. B. Shields, "Applications of Silicon Carbide for High Temperature Electronics and Sensors", NASA Jet Propulsion Laboratory, Tech Briefs 0145-319X, 1996.

[2] P.G. Neudeck, SiC Technology, The VLSI Handbook, The Electrical Engineering Handbook Series, CRC Press Inc., Boca Raton, FL (2007), pp. 5.1-5.34

[3] L.L. Snead, T. Nozawa, Y. Katoh, T.S. Byun, S. Kondo, D.A. Petti, J. Nucl. Mater., 371 (2007), pp. 329377.

[4] J.B. Malherbe, E. Friedland, N.G. Van Der Berg, J. Nucl. Instr. Meth. Phys. Res., B266 (2008), pp. 13731377

[5] E. Friedland, N.G. Van Der Berg, J.B. Malherbe, J.J. Hancke, J. Barry, E. Wendler, W. Wesch, J. Nucl. Mater., 410 (2011), pp. 24-31

[6] C.H. Andersson, R. Warren, Composites, 15 (1984), pp. 16-24

[7] K.A. Terrani, J.O. Kiggans, L.L. Snead, J. Nucl. Mater., 427 (2012), pp. 79-86

[8] R. L. Pearson, T. B. Lindemer, "Simulated fission product oxide behaviour in Triso-coated HTGR fuel", Oak Ridge National Laboratory, Report ORNL/TM-6741, 1979.

[9] C. Kamezawa, M. Hirai, M. Kusaka, M. Iwami, J. Labis, Appl. Surf. Sci., 237 (2004), pp. 607-611

[10] R. L. Pearson, R. J. Lauf, T. B. Lindemer, "The Interaction of Palladium, the Rare Earths, and Silver with Silicon Carbide in HTGR Fuel Particles”, Oak Ridge National Laboratory, Report ORNL/TM-8059, 1982. 
[11] L. Chen, G.W. Hunter, P.G. Neudeck, D. Knight, J. Vac. Sci. Technol., A16 (5) (1998), pp. 2890-2895

[12] R.W. Balluffi, J.M. Blakely, Thin Solid Films, 25 (1975), pp. 363-392

[13] T. Fukai, M. Naka, J.C. Schuster, Trans. JWRI, 25 (1996), pp. 59-62

[14] K. Bhanumurthy, R. Schmid-Fetzer, Composites, A32 (2001), pp. 569-574

[15] Y. Wang, A.H. Carim, J. Am. Ceram. Soc., 78 (1995), pp. 662-666

[16] T.C. Chou, A. Joshi, J. Wadsworth, J. Vac. Sci. Technol., A9 (1991), pp. 1525-1534

[17] F. Goesmann, R. Schmid-Fetzer, Mater. Sci. Eng., B46 (1997), pp. 357-362

[18] J.S. Park, K. Landry, J.H. Perepezko, Mater. Sci. Eng., A259 (1999), pp. 279-286

[19] L.R. Doolittle, Nucl. Instr. Meth., B9 (1985), pp. 344-351

[20] N.G. Van Der Berg, J.B. Malherbe, A.J. Botha, E. Friedland, Appl. Surf. Sci., 258 (2012), pp. 5561-5566

[21] R.C. Weast, Handbook of Chemistry and Physics, (67th ed.)CRC Press Inc., Boca Raton, FL (1986)

[22] V.I. Dybkov, Reaction Diffusion and Solid State Chemical Kinetics, The IPMS Publications, Kyiv (2002)

[23] F. Goesmann, R. Schmid-Fetzer, Semicond. Sci. Technol., 10 (1995), pp. 1652-1658

[24] R.D. Thompson, K.N. Tu, Thin Solid Films, 93 (1982), pp. 265-274

[25] J.B. Malherbe, J. Appl. Phys., 46 (2013), pp. 1-27

[26] E.J. Olivier, J.H. Neethling, J. Nucl. Mater., 432 (2013), pp. 252-260 